\title{
PENENTUAN JUMLAH PRODUKSI UD MEGA SAPUTRA MENGGUNAKAN FUZZY TSUKAMOTO
}

\author{
Ucik Airtanti $^{1}{ }^{\text {; }}$ Kustanto ${ }^{2}$; Hendro Wijayanto ${ }^{3)}$ \\ ${ }^{1)}$ Program Studi Sistem Informasi, STMIK Sinar Nusantara \\ ${ }^{2,3)}$ Program Studi Teknik Informatika, STMIK Sinar Nusantara \\ tantiairuci@gmail.com¹); kustanto@sinus.ac.id ${ }^{2}$; hendro@sinus.ac.id ${ }^{3)}$
}

\begin{abstract}
The breaking of bread production at UD Mega Saputra always rely on estimation only. Where with the many deficiencies found that resulted in losses for the company. Based on the inventory data and the number of requests, then designed a system of determining the amount of production using Tsukamoto method. In this system of production determination, there are three variables that are modeled, namely: demand, supply, and production. Steps to make Determination of Production Amount UD Mega Saputra Using Fuzzy Tsukamoto include designing the concept, collecting data, preparation of hardware and software, making modeling diagram, making application, testing, repairing, and completion. One example calculation using Tsukamoto method with type of mocca bread produce 70 bread, banana bread produce as many as 244 and donat produce an amount of 291 of bread per week.
\end{abstract}

Keywords : fuzzy tsukamoto, production amount, bread production, fuzzy

\section{PENDAHULUAN}

Untuk mendapatkan hasil yang memuaskan dibutuhkan peramalan yang akurat. Tanpa disadari, pelaku bisnis akan selalu membutuhkan peramalan dan memperkirakan permintaan konsumen. Oleh karena itu, dibutuhkan suatu sistem yang dapat membantu menyediakan data-data yang tepat untuk melengkapi tahapan dalam pengambilan keputusan dalam perusahaan tersebut. UD Mega Saputra adalah perusahaan yang bergerak dalam bidang Roti. Dalam hal ini UD Mega Saputra dalam menentukan keputusan produksi rotinya selama ini masih secara manual yaitu hanya mengandalkan perkiraan setiap hari. Namun hal ini dinilai kurang efektif dikarenakan dapat menyebabkan produksi roti menjadi berlebihan atau kekurangan setiap harinya. Jika terjadi produksi berlebihan maka roti tersebut akan kembali dijual esok hari dan roti tersebut mempunyai masa yang tidak bertahan lama. Sehingga pelanggan yang membeli roti tersebut akan komplain karena setelah membeli roti tersebut keesokan harinya roti tidak dapat dikonsumsi karena bejamur. Apabila terjadi kekurangan produksi roti pelanggan akan kecewa karena roti yang ingin dibeli sudah habis. Maka, dengan hal itu perusahaan akan kehilangan pelanggan dan mengalami kerugian. Berdasarkan uraian di atas, metode tsukamoto dirasa sangat cocok dan diharapkan dapat menyelesaikan permasalahan dalam penentuan produksi roti setiap waktunya. Penelitian ini bertujuan untuk menghasilkan sebuah sistem pendukung keputusan yang dapat membantu perusahaan dalam menentukan produksi roti.

\section{TINJAUAN PUSTAKA}

Metode Tsukamoto adalah perluasan dari penalaran monoton. Pada metode Tsukamoto, setiap konsekuen pada aturan yang berbentuk IF-THEN harus direpresentasikan dengan suatu himpunan fuzzy dengan fungsi keanggotaan yang monoton. Sebagai hasilnya, output hasil inferensi dari tiap-tiap aturan diberikan secara tegas (crisp) berdasarkan $\alpha$ - predikat (fire strength). Hasil akhirnya diperoleh dengan menggunakan rata-rata terbobot[1]. Dalam penelitian ini, penulis melakukan penelitian tentang Fuzzy Tsukamoto yang mengacu pada lima penelitian sebelumnya antara lain:

Penelitian yang dilakukan sebelumnya oleh Ali Mulyanto, dan Abdul Haris dalam judul Penerapan Metode Fuzzy Tsukamoto Untuk Menentukan Jumlah Jam Overtime Pada Produksi Barang(studi kasus: PT Asahi Best Base Indonesi)". Hasil dari penelitian tersebut adalah dengan permintaan 800 , persediaan 150 dan output 690 maka jumlah jam overtime yang harus dilakukan oleh departement produksi yaitu 2.5 jam[2] dari hasil penelitian di atas dapat diketahui keterkaitan antara penulis dengan penelitian sebelumnya adalah dengan mengunakan metode algoritma yang sama yaitu algoritma 
fuzzy Tsukamoto dan perhitungan yang sama dengan fuzzyfikasi, fuzzy inference, dan defuzzyfikasi, untuk perbedaannya adalah dimana hasil dari perhitungan pada fuzzy Tsukamoto akan menghasilkan hasil yang berbeda karena permasalahan dan data yang di gunakan berbeda.

Penelitian yang dilakukan oleh Maryaningsi, dkk dengan judul metode logika fuzzy tsukamoto dalam pengambilan keputusan penerimaan beasiswa. Hasil dari penelitian tersebut adalah hasil mengambil keputusan penerimaan beasiswa baru adalah 82 orang siswa dari jumlah penerimaan 100 orang siswa. Berdasarkan nomor urut dari 1 sampai 82 orang, sisa dari itu menunggu penerimaan beasiswa selanjutnya[3]. Dari hasil penelitian di atas dapat di ketehui keterkaitan antara penulis dengan penelitian sebelumnya adalah dengan mengunakan metode algoritma yang sama yaitu algoritma fuzzy Tsukamoto dan perhitungan yang sama dengan fuzzyfikasi, fuzzy inference, dan defuzzyfikasi, untuk perbedaannya adalah dimana hasil dari perhitungan pada fuzzy Tsukamoto akan menghasilkan hasil yang berbeda karena permasalahan dan data yang di gunakan berbeda.

Dari penelitian lainnya yang di lakukan oleh Mustika dalam judul Fuzzy Inference System Tsukamoto untuk pemilihan hotel bagi pendukung Asean Games 2018 di Palembang. Hasil penelitian keakuratan antara rangking pengguna dan rangking fuzzy sebesar 0,9512 [4] dari hasil penelitian tersebut dapat diketahui keterkaitan dengan penulis dengan penelitian sebelumnya adalah dengan mengunakan metode algoritma yang sama yaitu algoritma fuzzy Tsukamoto dan perhitungan yang sama dengan fuzzyfikasi, fuzzy inference, dan defuzzyfikasi, untuk perbedaannya adalah dimana hasil dari perhitungan pada fuzzy Tsukamoto akan menghasilkan hasil yang berbeda karena permasalahan dan data yang di gunakan berbeda.

Pada penelitian sebelumnya yang di lakukan oleh Adani Dharmawati, Hugo Aprilianto dengan judul Penerapan Metode Fuzzy Tsukamoto Untuk Prediksi Nilai Tukar Rupiah. Hasil dari penelitian Tersebut adalah nilai AFER sebesar $10,74 \%$, yang berarti ratarata simpangan yang terjadi antara data real dengan data hasil prediksi sebesar 10,74\%. Dengan simpangan paling besar $24,52 \%$ dan simpangan paling kecil yaitu 2,48\%[5]. Dari hasil penelitian atas dapat di ketahui keterkaitan dengan penulis dengan penelitian sebelumnya adalah dengan mengunakan metode algoritma yang sama yaitu algoritma fuzzy Tsukamoto dan perhitungan yang sama dengan fuzzyfikasi, fuzzy inference, dan defuzzyfikasi, untuk perbedaannya adalah dimana hasil dari perhitungan pada fuzzy Tsukamoto akan menghasilkan hasil yang berbeda karena permasalahan dan data yang di gunakan berbeda.

Pada penelitian sebelumnya yang di lakukan oleh Andrian Juliansyah dengan judul Penerapan metode Fuzzy Tsukamoto untuk memprediksi hasil kepala sawit (Studi Kasus di PT. Amal Tani Perkembunan Tanjung Putri- BAHOROK). Pada penelitian tersebut hasil yang di dapatkan adalah produksi minyak kelapa sawit yang harus diproduksi perusahaan PT.Amal Tani pada bulan oktober 2014 adalah 2093Ton[6]. Dari hasil penelitian tersebut dapat diketahui keterkaitan dengan penulis dengan penelitian sebelumnya adalah dengan mengunakan metode algoritma yang sama yaitu algoritma fuzzy Tsukamoto dan perhitungan yang sama dengan fuzzyfikasi, fuzzy inference, dan defuzzyfikasi, untuk perbedaannya adalah dimana hasil dari perhitungan pada fuzzy Tsukamoto akan menghasilkan hasil yang berbeda karena permasalahan dan data yang di gunakan berbeda.

\section{METODE PENELITIAN}

Untuk memperoleh informasi yang dibutuhkan dalam rangka mencapai tujuan penelitian dibutuhkan kegiatan pengumpuulan data, dibawah ini adalah jenis data yang penulis gunakan dalam penelitian.

\subsection{Data Primer}

Data primer adalah data yang diperoleh langsung dari UD mega Saputra yang menjadi obyek penelitian dalam hal ini adalah UD Mega Saputra data tersebut diantaranya data produksi, permintaan dan stok dalam menentukan jumlah produksi.

\subsubsection{Observasi}

Dari pengamatan langsung ini dapat dibuat sebuah kesimpulan bahwa metode manual sebelumnya yang dilakukan oleh pemilik membutuhkan perkiraan yang belum efektif dan dapat membuat rugi.

\subsubsection{Wawancara}


Hasil wawancara dengan pemilik UD Mega Saputra agar dibuat sistem yang lebih baik guna memfasilitasi dalam menentukan jumlah produksi yang lebih akurat.

\subsection{Output}

Hasil yang diperoleh setelah diterapkan sistem penentuan jumlah produksi di UD Mega Saputra dengan menggunkan sistem yang baru ini adalah sebagai berikut :

1. Database nilai yang baik dan aman yang dapat digunakan secara berkelanjutan.

2. Input nilai kriteria yang lebih cepat dan lebih akurat dapat dilakukan oleh pemilik UD Mega Saputra.

3. Percetakan hasil dari jenis-jenis dan jumlah roti yang akan di produksi.

\subsection{Pengujian Sistem}

Pengujian sistem ini bertujuan untuk menguji komponen sistem yang telah dirancang sebelumnya dan untuk memastikan bahwa setiap sistem telah berfungsi sesuai dengan yang diharapkan.

Pada tahan pengujia sistem penentuan jumlah produksi di UD Mega Saputra menggunakan pengujian fungsional

Bertujuan untuk menguji fungsi -fungsi khusus dari aplikasi yang dikembangkan, test input dan output untuk fungsi yang ada tanpa memperhatikan prosesnya pada pengujian ini kebenaran aplikasi yang diuji dilihat berdasarkan keluaran yang dihasilkan dari data masukan yang diberikan.

\section{HASIL DAN PEMBAHASAN}

\subsection{Desain Perancangan Sistem}

\subsubsection{Diagram Use Case}

Use Case giagram interaaksi antara aktor dalam sebuah system, serta menggambarkan pengelolaan sistem secara keseluruhan.

Admin/Pengelola adalah orang yangmengelola data-data master yang ada padasistem. Mengelola data produksi yangterberisi inpu, edit dan hapus variabelproduksi. Mengelola data persediaan yangberisi input, edit dan hapus variabel persediaan. Mengelola data permintaan yangterberisi input, edit dan hapus variable permintaan. Mengakses sistem yang berisimenginputkan jumlah pesanan, menginputkanpersedian dan perhitungan algoritma fuzzy.

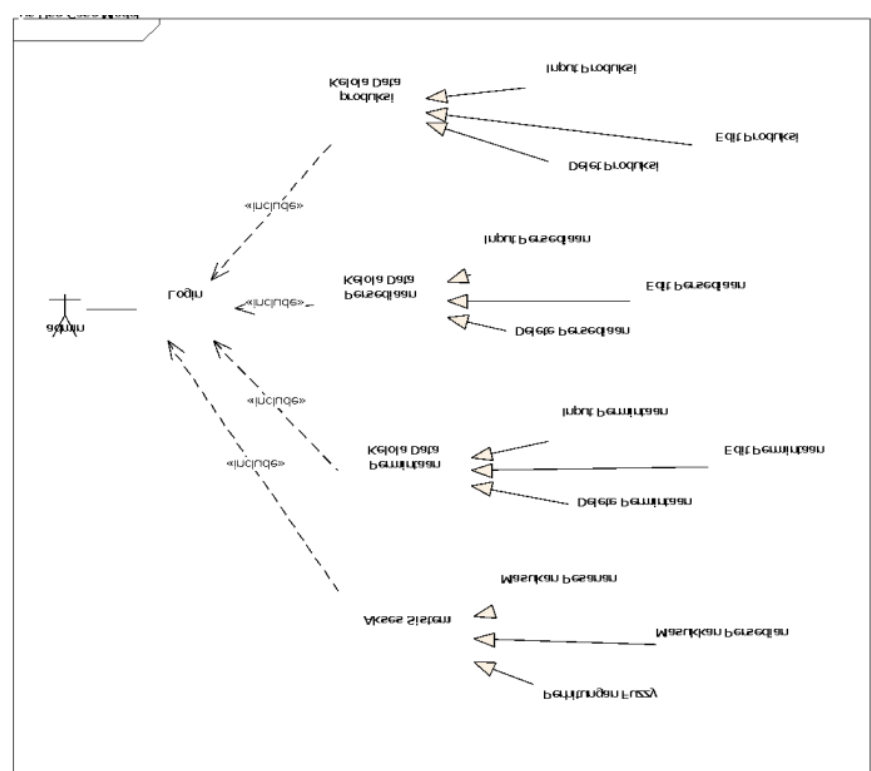

\section{Gambar 1. Use Case Diagram Penentuan Jumlah Produksi}

\subsubsection{Class Diagram}

Class Diagram adalah model statis yang menggambarkan struktur dan deskripssi class serta hubungan antar class atau diagram yang menggambarkan kelas-kelas dalam sebuah system dan hubungannya antara yang satu dengan yang lain, Class diagram berfungsi untuk memodelkan struktur kelas. seperti Gambar 2.

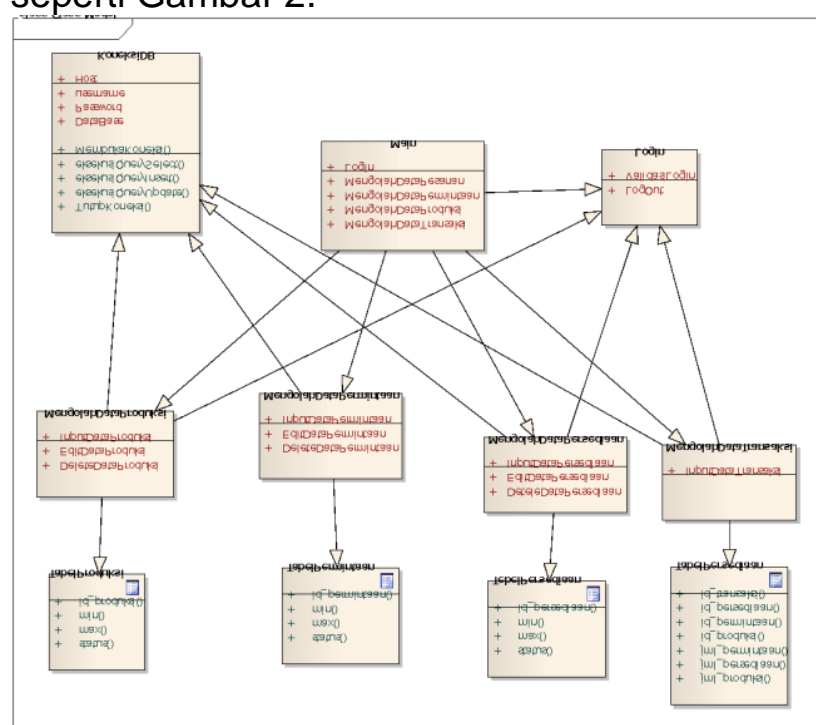

Gambar 2. Class Diagram penentuan jumlah produksi roti

\subsection{Implementasi}

Perusahan roti memiliki mesin yang mampu memproduksi jenis roti mocca hingga 100 buah perhari, tetapi untuk efesian mesin dan tenaga yang diharapkaan mesin tersebut paling tidak harus dapat membuat roti perharinya kurang lebih 50 buah. Masalah yang dihadapi UD Mega Saputra adalah 
permintaan roti yang tidak tentu dan bervariaasi antara 100 buah hingga 350 buah perhari. adapun tempat penyimpanan roti juga harus dibatasi yaitu paling banyak 120 buah roti per hari dan sesuai pengalaman maka persediaan roti tidak boleh kurang dari 70 buah roti dalam 1 hari. Pada hari tertentu UD Mega Saputra menerima pesanan roti sebanyak 150buah dan persedian digudang saat itu masih 100 buah. Hitunglah dengan menggunakan metode tsukamoto berapa buah roti yang harus diproduksi pada hari itu ? proses produksi UD Mega Saputra menggunakan 4 aturan fuzzy sebagai berikut:

RULE 1 : Jika permintaan turun dan persedian banyak maka produksi kurang

RULE 2 : Jika permintaan turun dan persedian sedikit maka produksi kurang

RULE 3 : Jika permintaan naik dan persedian banyak maka produksi tambah

RULE 4 : Jika permintaan naik dan persedian sedikit maka produksi tambah

Setelah pengguna memasukan data diform transaksi, maka akan tampil hasil jumlah yang akan diproduksi.

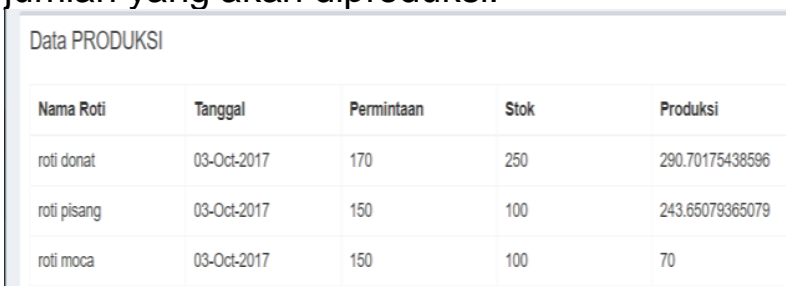

Gambar 3. Hasil Transaksi Produksi

Tampil Data Produksi

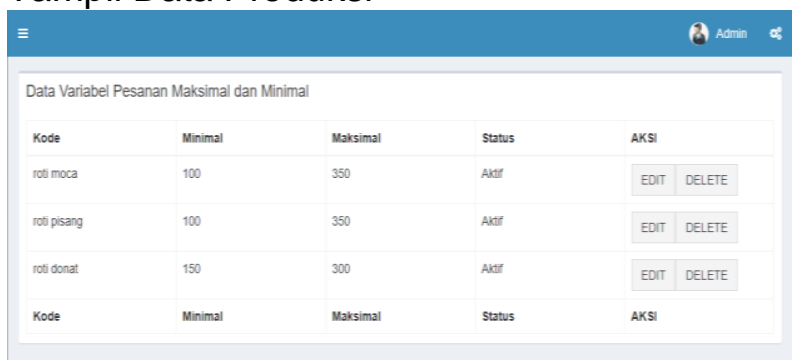

Gambar 4. Tampil Data Produksi

\subsection{Pengujian dan Penghitungan}

\subsubsection{Penghitungan Fuzzy Tsukamoto}

Penghitungan langkah demi langkah ditulis mulai dari Fuzzifikasi (pembentukan himpunan fuzzy), Fuzzy Inference (proses komposisi aturan), Defuzzyfikasi (penegasan hasil). Maka untuk menentukan jumlah produksi akan dilakukan perhitungan seperti berikut.

Tabel 1.Implementasi Logika Fuzzy

\begin{tabular}{|l|c|c|c|}
\hline & MINIMAL & MAKSIMAL & $\mathbf{X}$ \\
\hline PRODUKSI & 50 & 100 & $?$ \\
\hline STOK & 70 & 120 & 100 \\
\hline PERMINTAAN & 100 & 350 & 150 \\
\hline
\end{tabular}

1. Fuzzyfikasi (menentukan nilai keanggotaannya)

Rumus:

GrafikTurun $=\frac{\operatorname{Max}-x}{\operatorname{Max}-\min }$
GrafikNaik $=\frac{x-\operatorname{Min}}{\operatorname{Max}-\operatorname{Min}} \ldots . . .$.

a. Permintaan

$$
\begin{aligned}
& \text { MTurun }=\frac{\text { Max }-x}{\text { Max }-\min } \\
&=\frac{350-150}{350-100} \\
&= \frac{200}{250}=0,8 \\
& \mu \text { Naik }=\frac{x-\text { Min }}{\text { Max }- \text { Min }} \\
&=\frac{150-100}{350-100} \\
&=\frac{50}{250}=0,2
\end{aligned}
$$

b. Stok/persediaan

$$
\begin{aligned}
& \text { ? }_{\text {sedikit }}=\frac{\max -x}{\max -\min } \\
& \mu_{\text {Sedikit }}=\frac{120-100}{120-70} \\
& =\frac{20}{50}=0,4 \\
& \text { ? }_{\text {banyak }}=\frac{x-\text { Min }}{\max -\min } \\
& \mu \text { Banyak }=\frac{100-70}{120-70} \\
& =\frac{30}{50}=0,6
\end{aligned}
$$

\section{Fuzzy Interface System}

R.1: Jika permintaan Turun dan persediaan Banyak maka produksi Turun, karena turun maka menggunakan grafik turun $\frac{\max -x}{\max -\min }$ dan karena and maka nilai yang digunakan adalah nilai minimal $(0.8$ dan 0,6$)=\alpha_{1} 0,6$.

$$
\begin{aligned}
& \frac{\max -x}{\max -\min }=\alpha_{1} \\
& \frac{100-x}{100-50}=0,6 \\
& \frac{100-x}{50}=0,6 \\
& 100-x=30
\end{aligned}
$$




$$
\begin{aligned}
& 100=30-x \\
& X=100-30 \\
& X_{1=} 70
\end{aligned}
$$

R.2: Jika permintaan Turun dan persediaan Turun maka produksi Turun $(0,8$ dan 0,4).

$$
\begin{aligned}
& \frac{\max -x}{\max -\min }=\alpha_{2} \\
& \frac{100-x}{100-50}=0,4 \\
& \frac{100-x}{50}=0,4 \\
& 100-\mathrm{X}=20 \\
& 100=20-\mathrm{X} \\
& X=100-20 \\
& X_{2}=80
\end{aligned}
$$

R.3: Jika permintaan Naik dan persedian Naik maka produksi Naik, maka nilai minimal yang dicari $(0,2$ dan 0,6$)$.

$$
\begin{aligned}
& \frac{x-\min }{\max -\min }=\alpha_{3} \\
& \frac{x-50}{100-50}=0,2 \\
& \frac{x-50}{50}=0,2 \\
& X-50=10 \\
& 50=10+X \\
& X=50+10 \\
& X_{3}=60
\end{aligned}
$$

R.4: Jika permintaan Naik dan persedian Turun maka produksi Naik, Karena produksi Naik maka yang digunakan grafik Naik, maka nialai minimalnya $(0,2$ dan 0,4$)$.

$$
\begin{aligned}
& \frac{x-\min }{\max -\min }=\alpha_{4} \\
& \frac{x-50}{100-50}=0,2 \\
& \frac{x-50}{50}=0,2 \\
& X-50=10 \\
& 50=10+x \\
& X=50+10 \\
& X_{4}=60
\end{aligned}
$$

\begin{tabular}{|c|c|c|c|c|}
\hline \multicolumn{5}{|c|}{ Data PRODUKSI } \\
\hline Nama Roti & Tangalal & Peminitaan & Stok & Produksi \\
\hline rofidonat & 03:00:2017 & 170 & 250 & 20.701754385596 \\
\hline rotipisang & 03.00-2017 & 150 & 100 & 243.650709365079 \\
\hline rotimoca & 03.00+2017 & 150 & 100 & 70 \\
\hline
\end{tabular}

\section{Defuzzyfikasi}

$$
\text { DT }
$$$$
=\frac{\alpha 1 \cdot X 1+\alpha 2 . X 2+\alpha 3 \cdot X 3+\alpha 4 . X 4}{\alpha 1+\alpha 2+\alpha 3+\alpha 4}
$$

$D T=0,6 * 70+0,4^{\star} 80+0,2^{*} 60+0,2^{*} 60 /$

$0,6+0,4+0,2+0,2$

$D T=98 / 1,4=70$

Jadi jumlah roti mocca yang harus diproduksi oleh UD Mega Saputra sebanyak 70 buah roti

\subsubsection{Pengujian Validitas}

Pengujian validitas dilakukan untuk menyesuaikan apakah perhitungan manuaal dengan perhitungan sistem didapatkan hasil yang sama. Dalam penelitian ini telah diuji studi kasus yang dihitung secara manuall dan dari sistem. Dan berdasarkan dari uji coba studi kasus,maka dinyatakan baahwa sistem valid. Karena dari studi kasus yang diuji, hasil perhitungan sistem dan perhitungan manual mendapatkan hasil jumlah yang sama. Berikut rekapitulasi pengujian validitas dapat ditunjukkan pada Gambar 5.

Gambar 5. Hasil Pengujian Validitas Sistem

\section{PENUTUP}

Dengan adanya aplikasi yang dirancang UD Mega Saputra dapat dengan mudah menentukan produksi roti pada mingguminggu berikutnya sehingga perusahaan tidak mengalami kerugian yang besar. Dari hasil perhitungan Fuzzy Tsukamoto maka didapatkan jumlah produksi roti pisang 70 , roti mocca 244, dan roti pisang 291.

Untuk pengembang aplikasi selanjutnya diharapkan bisa menggunakan metode yang lain agar bisa membandingkan dengan metode fuzzy tsukamoto guna untuk menghasilkan presentase yang lebih akurat dan variatif.

\section{DAFTAR PUSTAKA}

[1] F. A. Minarni, "Prediksi Jumlah Produksi Roti Menggunakan Metode Logika Fuzzy (Studi Kasus: Roti Malabar Bakery)," Teknolf, vol. 4, 2016.

[2] A. H. Ali Mulyanto, "Penerapan Metode Fuzzy Tsukamoto Untuk Menentukan Jumlah Jam Overtime Pada Produksi Barang di PT Asahi Best Base Indonesia (ABBI) Bekasi," J. Inform. SIMANTIK, vol. 1, 2016.

[3] S. Maryaningsih, "Metode Logika Fuzzy Tsukamoto Dalam Sistem Pengambilan Keputusan Penerimaan Beasiswa," J. Media Infotama, vol. 9, 2013.

[4] Mustika, "Fuzzy Inference System Tsukamoto untuk pemilihan hotel bagi 
pendukung Asean Games 2018 di Palembang," Semin. Nas. Teknol. Informasi, Bisnis, dan Desain, 2016.

[5] H. A. Adani Dharmawati, "Penerapan Metode Fuzzy Tsukamoto Untuk Prediksi Nilai Tukar Rupiah," JUTISI, vol. 3, 2014.

[6] A. Juliansyah, "Penerapan metode Fuzzy Tsukamoto untuk memprediksi hasil kepala sawit (Studi Kasus di PT. Amal Tani Perkembunan Tanjung PutriBAHOROK)," Pelita Inform. Budi Darma, vol. IX, 2015. 